\title{
Toward an Understanding of "The Sex Game": The Effects of Gender and Self-Monitoring on Perceptions of Sexuality and Likability in Initial Interactions'
}

\author{
RICHARD J. HARNISH ${ }^{2}$ \\ Michigan State University/ARBOR, Inc.
}

\author{
ANTONIA AbBEY
}

Wayne State University

\author{
Kenneth G. DeBono \\ Union College
}

\begin{abstract}
Results of several studies indicate that men attribute more sexual meaning to heterosexual interactions than do women. Based on Abbey's (1982) findings, we hypothesized that males, in comparison to females, would attribute more sexuality to opposite-sex partners. Based on findings from several self-monitoring dating studies, we predicted that high self-monitors would rate their partners and themselves higher on sexuality and likability traits than would low self-monitors. A laboratory study was conducted in which mixed-sex pairs of participants discussed their likes and dislikes about college life. Participants then rated themselves and their opposite-sex partners on a set of sexuality and likability trait adjectives and indicated their interest in getting to know their partner better. Results supported the gender hypotheses, whereas they only partially supported the self-monitoring predictions. The self-monitoring effects on self-ratings of sexuality and partner ratings of likability are used to explain why high self-monitors are more successful than low self-monitors in establishing heterosexual relationships.
\end{abstract}

A number of researchers have found that men attribute more sexual meaning to heterosexual interactions than do women (Abbey, 1982; Abbey, Cozzarelli, McLaughlin, \& Harnish, 1987; Abbey \& Melby, 1986; Goodchilds \& Zellman, 1984; Rubin, 1970; Rytting, 1976; Shotland \& Craig, 1988; Sigal, Gibbs, Adams, \& Derfler, 1988; Study 2). For example, Abbey found that men perceived both male and female targets as being more seductive and promiscuous than did women. Men were also more sexually attracted to opposite-sex targets and eager to date them than were women. In subsequent

\footnotetext{
${ }^{1}$ Portions of this article were presented at the 60th Annual Meeting of the Eastern Psychological Association, Boston, MA, March 30-April 2, 1989. The authors wish to thank Paul Schmidt, Donna Wittl, Karen Ross, Bob Radaz, and Lisa Allen for their assistance in data collection. Appreciation is also extended to Galen Bodenhausen, Linda Jackson, and two anonymous reviewers for comments on an earlier draft of this article.

${ }^{2}$ Correspondence regarding this article should be addressed to Richard J. Harnish, who is now at ARBOR, Inc., Arbor Corporate Center, One West Third Street, Media, PA 19063, (215) $566-8700$.
}

\section{3}

Journal of Applied Social Psychology, 1990, 20, 16, pp. 1333-1344.

Copyright 1990 by V. H. Winston \& Son, Inc. All rights reserved. 
studies, Abbey and her colleagues (Abbey et al., 1987; Abbey \& Melby, 1986) found that gender differences in perceptions of female targets' sexual intent occurred across a range of situational and nonverbal cues including sex composition of the dyad, revealingness of target's clothing, interpersonal distance, eye contact, and touch.

In a conceptually similar study, Goodchilds and Zellman (1984) asked 14to 18-year-olds to indicate if a variety of cues which might occur on a date were indicative of an interest in engaging in sex with one's opposite-sex partner. They found that females were less likely than males to report revealing clothing worn by the female or male, males' prior reputation, locations such as the beach at night, activities such as drinking together, and behaviors such as tickling or complimenting one's partner as signs of sexual interest. Thus, their data suggest that women perceive situations and actions in a less sexual manner than do men.

What can account for these findings? Abbey (1982) argued that men sometimes mistake friendliness for seduction because they are socialized to search for evidence of women's sexual intent. Males' traditional responsibility for initiating dates and sexual activities may cause them to optimistically interpret ambiguous information as evidence of sexual attraction (Graverholz \& Serpe, 1985; Green \& Sandos, 1983). Traditional sex role stereotypes also enhance the likelihood that such misperceptions will occur. That is, women are expected to initially resist men's sexual advances even when they find them desirable and plan on reciprocating. In a complementary fashion, men have been taught that women prefer lovers who are forceful and dominant and that these strategies can turn a "no" into a "yes" (Berger, Searles, Salem, $\&$ Pierce, 1986; Weis \& Borges, 1973). Thus, men have learned that women do not always directly convey sexual interest and may even hide it.

Furthermore, the mass media presents men and women in consistently different ways. There is much more emphasis placed on women's physical attractiveness than on men's, and this standard is more rigidly applied to women (Silverstein, Perdue, Peterson, \& Kelly, 1986; Venkatesan \& Losco, 1975). From these presentations, men are taught to focus on females' physical attractiveness and sexual availability. Once men develop this sexual schema about women, it may act as a generalized expectancy causing them to interpret ambiguous information as evidence in support of their beliefs. Events which fit existing schemas are remembered better than those that do not and ambiguous evidence is likely to be interpreted in such a way that it confirms existing schemas (Bem, 1981).

While Abbey's (1982) results have been replicated in studies using photographs (A bbey et al., 1987; Abbey \& Melby, 1986) and videotapes (Shotland \& Craig, 1988; Sigal et al., 1988, Study 2), we are not aware of any studies which replicate the use of untrained individuals engaged in unscripted inter- 
actions. Although all of the studies mentioned above found evidence consistent with Abbey's finding that men perceive more sexuality in female targets than do women, results have been inconsistent regarding her finding that men attribute more sexuality toward a male target observed interacting in an initial interaction with a female target than do women. Abbey et al. (1987) suggested that the cues men use to evaluate sexual intent in heterosexual interactions may differ depending on the gender of the target. More cues may be required for men to perceive another man observed interacting with a woman as behaving in a sexual manner than to perceive a woman as behaving in a sexual manner. This would explain why the gender difference in perceptions of heterosexual intent typically occurred for male targets in those studies that used live interactions; such a setting provides a richer, more diverse set of stimuli including verbal and nonverbal cues. Thus, in the present study, we wished to replicate Abbey's original methodology in addition to examining a personality variable hypothesized to influence perceptions of heterosexual intent.

\section{Self-Monitoring}

The personality construct of self-monitoring (Snyder, 1987) may relate to individuals' propensity to perceive heterosexual intent in others' behavior. Research has demonstrated that high self-monitors possess a more extensive knowledge base than low self-monitors about other people and the type of behavior that they will typically manifest in a given setting (Snyder \& Cantor, 1980). As a possible result of possessing this extensive knowledge base, high self-monitors are quicker to form impressions of others they meet (Berscheid, Graziano, Monson, \& Dermer, 1976). Because high self-monitors are acutely aware of social cues, they may be more susceptible than low selfmonitors to societal influences and stereotypes when they develop their personal schemas. Thus, high self-monitors may be more likely than low selfmonitors to use ambiguous cues like physical attractiveness or style of dress when developing their schemas of sexual availability. High self-monitors' generalized expectancies about people may be more reflective of societal beliefs associated with sexual intent, and they may perceive others in a more sexualized manner than do low self-monitors when interpreting ambiguous information. In contrast, low self-monitors may be less likely to "jump to conclusions" based on minimal information that corresponds to societal stereotypes. Thus, it was hypothesized that high self-monitors would be more likely than low self-monitors to perceive their opposite-sex partners in a sexual manner.

High and low self-monitors also exhibit different interpersonal styles in dyadic interactions. Ickes and Barnes (1977) found that in initial heterosex- 
ual interactions, high self-monitors more than low self-monitors tended to speak first, initiate subsequent conversation, tailor their behavior to their partner, and were more directive in guiding the interaction. Given such differences, the initial interactions of high self-monitors can be characterized as smooth and pleasant because they are able to avoid or overcome awkward situations. As such, high self-monitors may come to perceive themselves and others as being likable. In turn, their interaction partners may react to them in a similar fashion, consistent with the notion of the self-fulfilling prophecy (Darley \& Fazio, 1980; Ross, Lepper, \& Hubbard, 1975; Snyder, Tanke, \& Berscheid, 1977). Because of this self-fulfilling prophecy, high self-monitors may have a greater opportunity to meet and become acquainted with others, and as a result, have a larger pool of potential sexual partners. Having a larger pool of potential sexual partners may explain why high self-monitors possess a more liberal and unrestricted orientation toward heterosexual relations. If their current relationship should sour, they can opt to terminate it and begin to cultivate another relationship with a new partner.

Might the use of these differing informational bases in interpreting behavior of others be reflected in the heterosexual attitudes and behavior of high and low self-monitors? It would seem so. Snyder, Simpson, and Gangestad (1986) found that high self-monitors, in comparison to low self-monitors, tended to have an unrestricted or liberal orientation toward heterosexual relations. That is, high self-monitors reported having a larger number of sexual partners within the preceding year, could envision themselves with a larger number of sexual partners within the next 5 years, were more likely to engage in sex with another person on only one occasion, and reported being more comfortable with casual sex than were low self-monitors.

As a step toward understanding "the sex game" (Bernard, 1969), a study was conducted in which the effects of gender and self-monit oring on perceptions of heterosexuality and likability were examined. An experiment was designed in which males and females engaged in an unstructured conversation for five minutes. Participants then rated their own and their opposite-sex partners' behavior. This study's design and procedures replicate those used in Abbey (1982), except observers were not included in the current study. The gender effects found in Abbey were comparable for actor and observers so it did not seem necessary to include both roles in the present study.

It was hypothesized that males would perceive themselves and their opposite-sex partners more sexually than would females. Men were expected to be more sexually attracted to their opposite-sex partners and interested in dating them than were women. High self-monitors were hypothesized to perceive more sexuality in themselves and their opposite-sex partners. High self-monitors were also expected to rate their opposite-sex partners and themselves higher on likability traits. 
Method

\section{Participants}

One hundred and ninety ( 94 males and 94 females) ${ }^{3}$ Michigan State University undergraduates participated in this study for course credit. Participants were scheduled in opposite-sex pairs such that none of the participants were acquainted with their partner. We classified 107 participants who scored 10 or greater on the 18-item Self-monitoring Scale as high self-monitors (53 males and 54 females) and 82 participants who scored 9 or less on the selfmonitoring Scale as low self-monitors ( 41 males and 41 females). For information on the Self-monitoring Scale's psychometric properties and a detailed discussion of assessment and validity issues, see Snyder and Gangestad (1986).

\section{Procedures}

As noted above, this study's procedures were similar to those used in Abbey (1982) except observers were not included. A pair of opposite-sex participants reported to a large anteroom with two adjoining cubicles where they were greeted by an experimenter. They were informed that the study concerned how the topic of conversation affected the smoothness of initial interactions and were told that their topic was their likes and dislikes about college life. They were then instructed that they would discuss this topic for 5 minutes and then complete some questionnaires that asked for their impressions of the interaction. The experimenter could hear enough of the conversation through the walls to be certain that all participants were taking their task seriously (i.e., discussing their likes and dislikes about college life). Upon reentry into the room, the experimenter gave each participant a questionnaire packet and each participant was shown to a separate cubicle to complete the questionnaire. Each cubicle door was closed to ensure privacy while they were responding to the questionnaires. It was hoped that this procedure would facilitate honesty in ratings on the dependent measures. When both participants had completed the questionnaires and had reentered the anteroom, they were told that the study was over, were debriefed, and thanked for their participation.

\section{Dependent Measures}

Participants first completed the 18-item version of the Self-monitoring Scale (Snyder \& Gangestad, 1986). The second measure was modeled after Abbey (1982). They were instructed to rate their opposite-sex partner's personality on 20 trait adjectives using a 7-point response scale with response

\footnotetext{
${ }^{3}$ Because of incomplete responses on the self-monitoring scale, one male participant's data were excluded from the subsequent analyses.
} 
options ranging from 1 (not at all) to 7 (very much). The items that formed a Sexuality Index were flirtatious, sexy, seductive, and promiscuous. The items that formed a Likability Index were kind, considerate, polite, sincere, and warm. Additional traits such as cheerful, assertive, and humorous and questions about the topic of conversation were included to obscure the true nature of the study. Participants were then asked to rate themselves on the same 20 traits. After completing these self-ratings, they were asked to indicate on the same 7-point scale the extent to which they: would like to become friends with their opposite-sex partner, would like to date their opposite-sex partner, and were sexually attracted to their opposite-sex partner.

\section{Results}

\section{Sexuality Findings}

A 2 (Sex of Subject) $\times 2$ (Self-monitoring) $\times 2$ (Ratings of self versus opposite-sex partner) repeated measure design was analyzed with participant's ratings of self versus opposite-sex partner as the repeated measure. A multivariate analysis of variance (MANOVA) was conducted which combined participant's ratings on the four sexual trait adjectives-flirtatious, sexy, seductive, and promiscuous - into Sexuality Indices for self and opposite-sex partner (interitem correlations ranged from .27 to $.62, p<.001$ ). There was a significant main effect for gender of subject, $F(4,178)=5.76, p<$ .001 . The a nalysis also revealed a significant main effect for the within-subject effect of rating self versus other, $F(4,178)=35.71, p<.001$. There were no other significant effects. To further examine the significant effects, univariate analyses of variance were conducted on self ratings and on opposite-sex partner ratings for each of the sexuality items.

As can be seen from the means presented in Table 1, male participants rated themselves as being significantly more flirtatious, sexy, seductive, and promiscuous than did females. Furthermore, males rated their opposite-sex partners as being significantly more sexy, seductive, and promiscuous than did females.

As can be seen in Table 2, high self-monitors rated themselves as being significantly more flirtatious and marginally more seductive than did low self-monitors. Contrary to predictions, high self-monitors did not rate their opposite-sex partners as being more flirtatious, sexy, seductive or promiscuous than did low self-monitors.

\section{Likability Findings}

A multivariate analysis of variance (MANOVA) was conducted which combined subject's ratings on the five likability trait adjectives-kind, con- 
Table 1

Mean Ratings of Self and Partner on Sexuality Traits as a Function of Sex of Subject

\begin{tabular}{lcccccc}
\hline \multirow{2}{*}{ Trait } & \multicolumn{3}{c}{ Self ratings } & \multicolumn{3}{c}{ Partner ratings } \\
\cline { 2 - 7 } & Male & Female & $F$-value & Male & Female & $F$-value \\
\hline Flirtatious & 4.56 & 4.14 & $3.66^{*}$ & 3.10 & 2.91 & ns \\
Sexy & 4.41 & 3.89 & $8.16^{* *}$ & 4.27 & 3.63 & $7.50^{* *}$ \\
Seductive & 3.92 & 3.31 & $8.36^{* *}$ & 3.21 & 2.49 & $10.91^{* * *}$ \\
Promiscuous & 3.98 & 3.06 & $15.93^{* * *}$ & 3.50 & 2.86 & $8.83^{* *}$ \\
\hline
\end{tabular}

Note. $d f=1,181 .{ }^{*} p<.05 .{ }^{* *} p<.007 .{ }^{* * *} p<.001$.

siderate, sincere, polite, warm -into Likability Indices for self and oppositesex partner (interitem correlations ranged from .47 to $.61, p<.001$ ). There was a significant main effect for self-monitoring, $F(5,182)=2.60, p<.03$. The analysis also revealed a significant main effect for the within-subject effect of rating self versus other, $F(5,182)=7.83, p<.001$. There were no significant interaction effects. To further examine the significant effects, univariate analyses of variance with repeated measures on participants' rating of self versus opposite-sex partner were conducted on each of the likability items.

As can be seen from the means presented in Table 3, high self-monitoring individuals tended to rate themselves as being more warm than did low self-monitoring individuals. In addition, high self-monitors rated their opposite-sex partners as being significantly more kind, sincere, polite and warm than did low self-monitors.

Table 2

Mean Ratings of Self and Partner on Sexuality Traits as a Function of Self-Monitoring

\begin{tabular}{lcccccc}
\hline \multirow{2}{*}{ Trait } & \multicolumn{3}{c}{ Self ratings } & \multicolumn{3}{c}{ Partner ratings } \\
\cline { 2 - 7 } & High & Low & $F$-value & High & Low & $F$-value \\
\hline Flirtatious & 4.70 & 4.01 & $10.06^{* *}$ & 3.03 & 2.98 & ns \\
Sexy & 4.27 & 4.03 & ns & 3.91 & 3.99 & ns \\
Seductive & 3.80 & 3.43 & $3.18^{*}$ & 2.93 & 2.77 & $\mathrm{~ns}$ \\
Promiscuous & 3.64 & 3.40 & $\mathrm{~ns}$ & 3.28 & 3.09 & $\mathrm{~ns}$ \\
\hline
\end{tabular}

Note. $d f=1,181 .{ }^{*} p<.07 .{ }^{* *} p<.002$. 
Table 3

Mean Ratings of Self and Partner on Likability Traits as a Function of Self-Monitoring

\begin{tabular}{lcccccc}
\hline \multirow{2}{*}{ Trait } & \multicolumn{3}{c}{ Self ratings } & \multicolumn{3}{c}{ Partner ratings } \\
\cline { 2 - 7 } & High & Low & $F$-value & High & Low & $F$-value \\
\hline Kind & 5.89 & 5.72 & ns & 5.82 & 5.55 & $3.65^{* *}$ \\
Considerate & 5.73 & 5.81 & ns & 5.69 & 5.48 & ns \\
Sincere & 5.92 & 5.72 & ns & 5.53 & 5.17 & $4.74^{* *}$ \\
Polite & 5.83 & 5.71 & ns & 5.96 & 5.59 & $6.07^{* *}$ \\
Warm & 5.67 & 5.37 & $3.55^{*}$ & 5.32 & 4.82 & $7.48^{* * *}$ \\
\hline
\end{tabular}

Note. $d f=1,181 .{ }^{*} p<.06 .{ }^{* *} p<.05 .{ }^{* * *} p<.007$.

\section{Desired Relationship Findings}

Participants were asked if they would like to become friends with their opposite-sex partner, if they would like to date their opposite-sex partner, and if they were sexually attracted to their opposite-sex partner. A 2 (Sex of Subject) $\times 2$ (Self-monitoring) analysis of variance (ANOVA) was conducted on each of the relationship items. The analyses revealed a significant main effect for sex of subject, $F(1,185)=4.95, p<.03$, on the friendship variable, such that females were more interested in becoming friends with their opposite-sex partners $(M=5.64)$ than were males $(M=5.24)$. There were no significant effects for sex of subject of self-monitoring on whether they would like to date their opposite-sex partner. The analysis performed on whether participants were sexually attracted to their opposite-sex partners revealed a significant sex of subject effect, $F(1,184)=28.98, p<.001$, indicating that males were more sexually attracted to their opposite-sex partners $(M=3.50)$ than were females $(M=2.29)$.

\section{Discussion}

The results from this study replicate and extend Abbey's (1982) previous findings. Men perceived their female partners and themselves as more seductive, sexy, and promiscuous than women perceived their male partners or themselves. Men were also more sexually attracted to their opposite-sex partners than were women. In Abbey and her colleagues' past research (Abbey, 1982; Abbey et al., 1987; Abbey \& Melby, 1986), men have consis- 
tently perceived females in a more sexual manner than women have perceived males, regardless of whether the male interacted with the female, observed the female interacting with another male, or viewed photographs of male-female or female-female dyads. In contrast, men perceived more sexuality than women in males' behavior only when observing males and females engaging in actual heterosexual interactions (Abbey, 1982) or when naturalistic videotapes were used (Shotland \& Craig, 1988). The study presented here used actual interactions and replicated the gender difference in perceptions of the male target found in Abbey (1982). That is, in the present study, in which live interactions occurred, males perceived themselves (the male target) as behaving in a more sexualized manner than did females. This supports the argument that more cues are required for males to perceive male targets sexually than for them to perceive female targets sexually. An important direction for future research is to determine what these cues are. Focus groups could examine videotapes of male-female dyads' interactions and participants could describe the types of cues they were using to make their sexual judgments. This is the type of information of which people may not have precise knowledge (Nisbett \& Ross, 1980), but such preliminary information could be used to develop staged interactions which systematically varied these cues.

There are important differences in the implications of the finding that men perceive females more sexually than women do as opposed to the finding that men perceive everyone more sexually than women do. Both suggest that males may misperceive females' friendliness as seduction, an error which can create unpleasant interactions and sometimes lead to date rape (Abbey, 1987). The latter, however, also suggest a general world view more systemic than the first hypothesis suggests. It implies that sexual schema are more salient to men than to women and will be applied in a wide variety of settings based on a minimal number of supportive cues. Societal stereotypes of males as more interested in sex than females and as more driven by sexual concerns, support the latter hypothesis (Byrne, 1977; Gross, 1978; Peplau, Rubin, \& Hill, 1977; Ruble, 1983).

Self-monitoring had the predicted main effects on self-ratings of sexuality but not on partner ratings. High self-monitors rated themselves as being more flirtatious and seductive than did low self-monitors. High self-monitors also rated their opposite-sex partners as being more kind, sincere, polite, and warm than did low self-monitors. Combined, these two sets of findings help explain why high self-monitors possess a more liberal and unrestricted orientation toward sexual relations than do low self-monitors. This study's results suggest that the self-perception of being flirtatious and seductive coupled with perceptions of opposite-sex others as being kind, sincere, polite, and warm may interact, providing high self-monitors with maximum opportunities for establishing sexual relationships. Such perceptions create an optimistic 
attitude in high self-monitors which cause them to treat others in a friendly way which in turn creates a self-fulfilling prophecy. In comparison, the self and other perceptions of low self-monitors may interact causing them to interpret their number of potential sexual partners as being rather limited and to consequently behave in ways which further limits their opportunities.

Supporting this conclusion is a study conducted by Snyder and Simpson (1987) in which high and low self-monitors were asked, "If you could change dating partners, which individual, if any, would you substitute for?" High self-monitors reported a greater willingness to substitute a friend in the place of their current romantic partner. And when they were asked, "If you could ideally form a close, intimate dating relationship with either (name of current dating partner) or (name of a friend of the opposite sex), who would you choose?" High self-monitors once again chose the friend rather than their current dating partner. Thus, it appears that high self-monitors' uncommitted attitude toward their romantic relationships stems at least partially from their more optimistic perception of having a greater number of available potential sexual partners.

\section{Directions for Future Research}

An important direction for future research involves establishing predictors of the likelihood of perceiving sexual intent when it was not intended. Several studies indicate that while misperceptions of sexual intent are usually quickly resolved, they can lead to date rape (Abbey, 1987; Muehlenhard \& Linton, 1987). It is easy to imagine how a series of misperceptions could occur throughout an evening (e.g., his date wears a low cut blouse, drinks alcohol, is willing to go to his apartment, is willing to kiss him) that might leave a male convinced that his date has been seducing him. If she refuses his advances, he may feel justified in forcing sex onto her because he feels led on (Abbey, in press). At the end of the brief initial interactions developed during this study, women felt mostly friendship while men felt mostly sexual attraction. This suggests that men and women often evaluate shared experiences quite differently. Prevention efforts designed to help men and women more accurately assess when someone of the opposite sex is sexually attracted to them could reduce the frequency of misperceptions of sexual intent.

\section{References}

Abbey, A. (1982) Sex differences in attributions for friendly behavior: Do males misperceive females' friendliness? Journal of Personality and Social Psychology, 42, 830-838.

Abbey, A. (1987). Misperceptions of friendly behavior as sexual intent: A 
survey of naturally occurring incidents. Psychology of Women Quarterly, 11, $173-194$.

Abbey, A. (in press). Misperception as an antecedent of acquaintance rape: A consequence of ambiguity in communication between women and men. In A. Parrot (Ed.), Acquaintance rape. New York: John Wiley \& Sons.

Abbey, A., Cozzarelli, C., McLaughlin, K., \& Harnish, R. J. (1987). The effect of clothing and dyad sex composition on perceptions of sexual intent: Do women and men evaluate these cues differently? Journal of Applied Social Psychology, 17, 108-126.

Abbey, A., \& Melby, C. (1986). The effect of non-verbal cues on gender differences in perceptions of sexual intent. Sex Roles, 15, 283-298.

Bem, S. L. (1981). Gender schema theory: A cognitive account of sex typing. Psychological Review, 88, 354-364.

Berger, R. J., Searles, P., Salem, R. G., \& Pierce, B. A. (1986). Sexual assault in a college community. Sociological Focus, 19, 1-26.

Bernard, J. (1969). The sex game. London: Leslie Frewin Publishers.

Berscheid, E., Graziano, W., Monson, T. C., \& Dermer, M. (1976). Outcome dependency: Attentions, attribution, and attraction. Journal of Personality and Social Psychology, 34, 978-989.

Byrne, D. (1977). Social psychology and the study of sexual behavior. Personality and Social Psychology Bulletin, 3, 3-30.

Darley, J. M., \& Fazio, R. H. (1980). Expectancy confirmation processes arising in the social interaction sequence. American Psychologist, 35, 867881.

Goodchilds, J. D., \& Zellman, G. L. (1984). Sexual signaling and adolescent aggression in adolescent relationships. In N. M. Malamuth \& E. Donnerstein (Eds.), Pornography and sexual aggression (pp. 233-243). Orlando, FL: Academic Press.

Graverholz, E., \& Serpe, R. T. (1985). Initiation and response: The dynamics of sexual interaction. Sex Roles, 12, 1041-1059.

Green, S. K., \& Sandos, P. (1983). Perceptions of male and female initiators of relationships. Sex Roles, 9, 849-852.

Grcss, A. E. (1978). The male role and heterosexual behavior. Journal of Social Issues, 37, 87-107.

Ickes, W., \& Barnes, R. D. (1977). The role of sex and self-monitoring in unstructured dyadic interactions. Journal of Personality and Social Psychology, 35, 315-330.

Muehlenhard, C. L., \& Linton, M. A. (1987). Date rape and sexual aggression in dating situations: Incidence and risk factors. Journal of Counseling Psychology, 34, 186-196.

Nisbett, R., \& Ross, L. (1980). Human inference: Strategies and shortcomings of social judgment. Englewood Cliffs, NJ: Prentice-Hall. 
Peplau, L. A., Rubin, Z., \& Hill, C. T. (1977). Sexual intimacy in dating relationships. Journal of Social Issues, 33, 86-109.

Ross, L.,Lepper, M. R., \& Hubbard, M. (1975). Perseverance in selfperception and social perception: Biased attributional process in the debriefing paradigm. Journal of Personality and Social Psychology, 23, 880-892.

Rubin, Z. (1970). Measurement of romantic love. Journal of Personality and Social Psychology, 16, 265-273.

Ruble, T. L. (1983). Sex stereotypes: Issues of change in the 1970's. Sex Roles, 9, $397-402$.

Rytting, M. B. (1976, May). Sex or intimacy: Male and female versions of heterosexual relationships. Paper presented at the meeting of the Midwestern Psychological Association.

Shotland, R. L., \& Craig, J. M. (1988). Can men and women differentiate between friendly and sexually interested behavior? Social Psychology Quarterly, 51, 66-73.

Sigal, J., Gibbs, M., Adams, B., \& Derfler, R. (1988). The effect of romantic and nonromantic films on perceptions of female friendly and sexual behavior. Sex Roles, 19, 545-554.

Silverstein, B., Perdue, L., Peterson, B., \& Kelly, E. (1986). The role of the mass media in promoting a thin standard of body attractiveness for women. Sex Roles, 14, 519-532.

Snyder, M. (1987). Public appearances/private realities: The psychology of self-monitoring. New York: W. H. Freeman.

Snyder, M., \& Cantor, N. (1980). Thinking about ourselves and others: Self-monitoring and social knowledge. Journal of Personality and Social Psychology, 39, 222-234.

Snyder, M., \& Gangestad, S. (1986). On the nature of self-monitoring: Matters of assessment, matters of validity. Journal of Personality and Social Psychology, 51, 125-139.

Snyder, M., \& Simpson, J. A. (1987). Orientations toward romantic relationships. In D. Perlman \& S. Duck (Eds.), Intimate relationships: Development, dynamics and deterioration (pp. 45-62). Beverly Hills, CA: Sage.

Snyder, M., Simpson, J. A., \& Gangestad, S. (1986). Personality and sexual relations. Journal of Personality and Social Psychology, 51, 181-190.

Snyder, M., Tanke, E. D., \& Berscheid, E. (1977). Social perception and interpersonal behavior: On the self-fulfilling nature of social stereotypes. Journal of Personality and Social Psychology, 35, 656-666.

Venkatesan, M., \& Losco, J. (1975). Women in magazine ads: 1959-71. Journal of Advertising Research, 15, 49-54.

Weis, K., \& Borges, S. S. (1973). Victimology and rape: The case of the legitimate victim. Issues in Criminology, 8, 71-115. 